\title{
POOLING ADMINISTRATIVE RESOURCES THROUGH EU REGULATORY NETWORKS
}

\begin{abstract}
Do EU administrative networks help to preserve executive power at the member-state level, or centralize executive power at the EU level? This article examines how resource pooling takes place in the European Medicines Regulatory Network (EMRN), and the relevance of organizational structure in explaining this. By doing so the article adds both empirically and theoretically to the literature. The article presents new insights on intra-network decision behaviour, showing how network participants, under the coordination of an EU agency, pool resources by sharing knowledge, information, practices and experiences, and by routinized division of labour. Furthermore, applying an organizational perspective the article identifies some organizational structural factors that facilitate resource pooling and contribute to centralization of the EMRN. The findings thus have implications for the debate on the effects of establishing EU regulaory networks.
\end{abstract}

Keywords: European Union, regulatory networks, administrative integration, national agencies, organizational perspective. 


\section{INTRODUCTION}

Networks have become a pervasive feature of the EU's administrative system. Since the 1990s the number of EU administrative networks has increased rapidly, in multiple policy fields (Levi-Faur 2011). Networks constitute organizational settings within which EU executive bodies co-operate with regulatory authorities from EU and EEA member-states on EU policy formulation and implementation. They are characterized by varying degrees of formality, institutionalization and decision-making competencies. However, scholars disagree on the effects of such administrative arrangements for EU policy administration and, ultimately, EU executive power. The conventional, intergovernmental understanding holds that networks represent a type of arrangement that contributes to keeping EU policy administration and executive power decentralized in the hands of the member-states (Kassim and Menon 2010; Kelemen and Tarrant 2011). Although the European Commission ('the Commission'), the EU's main executive body, develops policy proposals and oversees member-state implementation, public administration has traditionally been seen as a core state power (Genschel and Jachtenfuchs 2013). Formulating and implementing public policy in the EU is considered a prerogative of member-states and national administrations (Trondal and Peters 2013: 295). Networks are the preferred steering arrangement when memberstates are least interested in delegating power 'upwards'; such networks fulfil similar functions as the Commission, but are more subject to control by national governments (Eberlein and Grande 2005; Kassim and Menon 2010; Kelemen and Tarrant 2011). Especially post-Maastricht, EU member-states have been reluctant to delegate powers to the Commission, resulting in a reduction of its resources and capacity for independent action. EU agencies and networks are preferred because they contain mechanisms for member-state representation as part of their governance structure, to ensure member- 
state control and avoid supranational decision-making (Bickerton et al. 2014; Kassim et al. 2013; Kassim and Menon 2010; Kelemen 2002). In this perspective, administrative decision behaviour is conditioned by formal delegation and legal arrangements. As a consequence intra-network behavioural patterns remain intergovernmental and administrative decision-making decentralized.

However, a growing number of studies indicate that intra-network behavioural patterns are not solely intergovernmental, but are supplemented or replaced by more integrated patterns that cross national borders and levels of government. Seeing decision behaviour as shaped by organizational structure, scholars argue that centralized behavioural patterns may occur due to the way networks are organized (see Egeberg 2006). Issuespecific networks establish horizontal and vertical relationships for co-operation and interaction between EU-level and sub-national actors beyond the control of memberstate governments. By creating opportunities for integration and mutual influence among actors like national agencies (NAs), the Commission and EU agencies, networks represent a type of arrangement that might contribute to a centralization of administrative decision behaviour, transforming policy administration and executive power at the EU level (Egeberg 2006; Trondal 2010). The effect of networks on their members remains largely understudied (Maggetti 2014), but two 'network effects' have been identified thus far. One effect is the development of double-hatted NAs that serve the Commission in addition to their national ministries, strengthening the Commission as a core executive and its ability to act independently of member-states (Curtin and Egeberg 2008; Egeberg 2006). A second effect concerns the strengthening of NAs' position vis-à-vis their parent ministries in national administrative systems, due to resources that NAs gain through intra-network co-ordination (Bach et al. 2015; Bach 
and Ruffing 2013; Danielsen and Yesilkagit 2013; Newman 2008; Yesilkagit 2011). The fact that NAs are able to gain resources through networks indicates intra-network integration and mutual influence, and resource pooling has been referred to as a network phenomenon (see for instance Bach et al. 2015; Ossege 2015). However, how and why networks facilitate resource pooling has not been studied explicitly. Aiming to fill this gap in the literature, this article enquires into resource pooling in the European Medicines Regulatory Network (EMRN), and the relevance of organizational structure in explaining it.

The article contributes empirical and theoretical insights to the literature on EU networks by providing new knowledge on intra-network decision behaviour and what factors might condition it. The article offers a study of intra-network decision behaviour in the EMRN, where the Commission, the European Medicines Agency (EMA) and national medicines regulatory agencies co-operate in formulating and implementing EU pharmaceutical policy. Heavily characterized by the kinds of mechanisms and memberstate representation expected to lead to member-state control and intergovernmental, decentralized behavioural patterns, the network is a least-likely case for organizational structure promoting centralization of decision behaviour in the network. Yet, the findings reveal a type of intra-network decision behaviour that involves integration and mutual influence in ways that one would not expect from an intergovernmental perspective. Administrative resources are pooled in two ways through the EMRN: first, network participants routinely interact and share valuable assets such as knowledge, information, practices and experiences. Second, there is a routinized division of labour in the network, with network participants mutually adapting and specializing in different types of tasks and different fields of expertise. Both take place under the co- 
ordination of the EMA. This represents new empirical insights on intra-network decision behaviour. NA pooling of administrative resources under the co-ordination of an EU agency indicates administrative integration and mutual influence across levels of government and national borders, and can be understood as a centralization of executive power at the EU level within the pharmaceutical sector. This can be seen an indication of an emerging multilevel union administration (Egeberg 2006: Trondal 2010).

Furthermore, the article identifies certain structural factors that may explain resource pooling and supports the claim that organizational structure may facilitate centralized intra-network decision behaviour. Firstly, horizontal specialization, or shared sector affiliation among network participants, encourages resource pooling by focusing actors' attention towards common issues, challenges and solutions. Secondly, the vertical specialization of national administrative systems facilitates resource pooling, enabling NAs to operate relatively independently in the network and focus on scientific-technical concerns rather than national, political ones. Thirdly, resource pooling is facilitated by the lack of organizational capacities in several NAs and the potential benefits of economies of scale, while the presence of considerable organizational capacity in EMA enables the agency to co-ordinate and supervise resource pooling. The fact that resource pooling takes place in the EMRN despite strong member-state control mechanisms indicates that resource pooling also may occur in other networks normally perceived to be characterized by intergovernmental, decentralized decision behavioural patterns. That is not to say that resource pooling is conditioned by organizational structure alone. However, rather than assuming that intra-network decision behaviour is conditioned merely by formal delegation and legal arrangements, this article shows that applying an organizational perspective to the study of EU administrative networks contributes to a 
deeper understanding of the effects of establishing such administrative arrangements for EU policy administration and, eventually, EU executive power.

The article is organised as follows. The first section outlines the analytical framework based on an organizational perspective. The second section describes the case, methods and data. The third section presents the empirical findings on how network participants pool resources under the co-ordination of EMA. The fourth section provides a discussion of the importance of organizational structure in explaining resource pooling. Finally, the wider implications of the study for the literature and the decentralizationcentralization debate are discussed in the conclusion.

\section{THE IMPORTANCE OF STRUCTURE: AN ORGANIZATIONAL}

\section{PERSPECTIVE}

An organizational perspective is helpful in studying the relationship between networks and intra-network decision behaviour. Based on the claim that organizational structure shapes decision behaviour, the organizational perspective provides some expectations as to how and why resource pooling may occur. Intra-network decision behaviour, the dependent variable, is understood as the many choices and decisions that EU and national officials make in performing their tasks related to EU policy administration. Organizational structure expresses impersonal role expectations and norms for action that are expected to influence which action alternatives are chosen: what is emphasized and paid attention to, and what is not. The point of departure is that specific structural dimensions systematically lead daily decision processes in certain directions, making some choices more likely than others. Structural designs are thus expected to 'route' information exchange, co-ordination processes and conflict resolution (Egeberg 2012: 
161). A key assumption here is that individuals are boundedly rational in decisionmaking, not capable of overseeing all alternatives and possibilities. When choosing between different alternatives for action, individuals' organizational context can simplify complex problems by narrowing down and sorting feasible and unfeasible policy options (Egeberg 2012). From the theoretical perspective and previous studies, the relevant structural dimensions here are horizontal and vertical specialization as well as organizational capacity.

\section{Horizontal specialization}

Horizontal specialization refers to how tasks are distributed at one level. There are various ways in which tasks may be distributed horizontally, for example in relation to geography or purpose (sector). While specialization according to geography is expected to cause spatial perspectives and encourage policy-makers to focus on territorial concerns, specializing according to purpose is expected to foster sectoral horizons among decision-makers and policy standardization across territorial units (Egeberg 2012: 159). Studies substantiate that organizing according to purpose focuses individual decision-makers' attention and behaviour along sectoral lines, with less attention to other (for instance territorially-based) concerns and problems (for an overview see Egeberg 2012). Horizontal specialization may also facilitate interaction and identification among organizations that are organized according to sector. Even if located in different countries and at different levels of government, they face similar problems and needs for solutions, which again facilitates cooperation that can span organizational and national borders (Egeberg 2006). Thus, horizontal specialization is expected to encourage resource pooling among network participants: since the EMRN brings together officials from units (the Commission, EU agencies and NAs) with 
compatible organizational structures and shared sector affiliation, they are expected to focus on similar problems and solutions.

\section{Vertical specialization}

Vertical specialization concerns the intended division of labour across hierarchical levels (Egeberg 2012: 159). Establishing agencies outside ministries indicates that some separation of political and scientific-technical decision-making is intended, but is not in itself a guarantee of de facto agency autonomy. Studies indicate, however, that agency officials exercise discretion differently from their ministerial colleagues, by attaching greater importance to professional and expert considerations and to user or client interests than to political concerns (Egeberg 2012). External vertical specialization reduces political control and provides more leeway for expert-based decision-making, but politicization of issues may increase ministerial steering of agency activities. NAs that are not only formally but also in practice somewhat decoupled from direct political steering may constitute an administrative infrastructure open to re-coupling into new organizational configurations, partly bypassing their parent ministries (Trondal 2014: 547). Vertical specialization may facilitate network decision behaviour that spans organizational and national borders, whereas integrated ministries would not be conducive to such a development (Egeberg and Trondal 2009: 686). Thus vertical specialization is expected to encourage resource pooling among network participants: since national agencies participating in the EMRN are vertically separated at the national level, they are expected to operate relatively freely in the EMRN, and NA officials are expected to focus on and promote professional-technical rather than political concerns, issues and views. 


\section{Organizational capacity}

The size of an organization, or the number of roles to be filled, may indicate its capacity to initiate policies, develop alternatives, or to implement final decisions (Egeberg 2012: 159). Administrating a policy area requires some minimum measure of organized attention, organizational autonomy and capacity for gathering area-relevant information as well as preparing decisions, actions and proposals and implementing actions, programmes and policies (Gornitzka 2009: 110). The building blocks of administrative capacity are policy expertise, professional staff, financial resources and some degree of organizational continuity and experience (Martens 2008b). Two expectations can be outlined regarding the importance of organizational capacity. First, studies show that NAs gain capacity and strengthen their autonomy vis-à-vis their national superiors and challenge ministries in specific policy-issues, also in the policy-formulation phase (Bach et al. 2015; Bach and Ruffing 2013; Danielsen and Yesilkagit 2013; Newman 2008; Yesilkagit 2011). NAs exchange information and best practices with actors who conduct similar scientific-technical tasks and focus on comparable professional concerns (Egeberg 2006; Gulbrandsen 2011). Networks may also help to reinforce NAs' regulatory powers in national administrative systems (Maggetti 2014), and affect domestic adoption of standards (Maggetti and Gilardi 2011). Influence and input from EU executive bodies and networks are especially important to NAs that lack administrative capacity and newcomers with little experience in the EU system (Martens 2008b). In the EMRN, NA lack of organizational capacity - expertise, staff, financial resources or experience - is expected to encourage resource pooling among network participants. 
Second, studies show that EU agencies have become pervasive features of the executive order (Busuioc et al. 2012) and are treated as integral parts of the Commission's administration (Egeberg et al. 2015). They have expanded regarding tasks, responsibilities and personnel; they embody executive capacity for action and execution of policy, and may be directly involved in the work of NAs (Egeberg et al. 2012; Versluis 2012). Large organizational capacity has enabled EU executive bodies to influence decision behaviour in networks and 'double-hatted' national agencies (Egeberg et al. 2012; Levi-Faur 2011; Martens 2006; Martens 2008a; 2008b; Versluis 2012), boosting harmonization among member-states in the implementation phase also where the legal basis for Community action is weak. EU agency strength is related to centrality in EU decision-making procedures and unique position as permanent nexus, a position difficult for national administrative actors to fill (Gornitzka 2009: 124). EU agencies integrate national administrative bodies into their operations by providing structures for co-operation between the supranational and national level, and among national authorities (Hofmann and Türk 2007: 258), facilitating behavioural patterns that span levels of government and national borders. In the EMRN, EMA is expected to facilitate resource pooling among network participants by being an important hub with organizational capacity to influence intra-network decision behaviour.

\section{CASE, METHODS AND DATA}

The article presents a study of the EMRN, a case particularly suited for investigating the relevance of organization structure in facilitating resource pooling. The EMRN is understood as a least-likely case for centralized decision behaviour: the Commission has been granted some decision power in this field, but with its many mechanisms for member-state control the network could be expected to be characterized by 
decentralized decision behaviour (Gerring 2007: 116-9). A comprehensive regulatory system for medicines has been institutionalized at the EU level since the first directive in 1965 established that medicines must receive a marketing authorization (MA) before entering the market, based on the evaluation of safety, therapeutic efficacy and quality of the product (Krapohl 2008: 70; Hauray and Urfalino 2009). The regulatory system now covers the complete life-cycle of a medicine from product development, testing and manufacturing to approval for sale by MA and post-market monitoring of adverse effects (Hauray 2013). Initially the system was based on mutual recognition of MAs, but did not function properly due to differences in member-state health policies and professional traditions. This was the reason for introducing a centralized procedure (CP) for certain products, with the Commission as decision-taker, and for establishing EMA in 1993 (functioning from 1995) (Krapohl 2008). Both the Commission's and EMA's activities in the system rely heavily on member-state involvement. Commission decisions on MAs are subject to comitology procedure, approved by a committee composed of member-state ministry representatives, and are made on the basis of scientific opinions from the EMA. EMA activities are supervised by its management board, also composed of member-state representatives. In addition to its secretariat and board, EMA consists of seven scientific committees, 26 working parties, 9 scientific advisory groups and several ad hoc advisory groups, composed of NA representatives (EMA 2014a). EMA provides scientific support to the Commission in EU policy formulation, and administers safety monitoring (pharmacovigilance) and supervision (inspections) as well as MA procedures (the $\mathrm{CP}$ and arbitration in procedures based on mutual recognition of nationally issued MAs). This relates to product assessments that constitute the basis for MAs as well as recommendations and advice on guidelines, policy development and international affairs. For each case concerning product 
assessments, two rapporteurs are appointed among the NAs to evaluate applications and provide scientific assessment reports. Scientific opinions are agreed on and ratified by voting in committees before being submitted by the EMA secretariat to the Commission for final decision (Hauray 2013: 86). These opinions are basically rubber-stamped into Commission decisions (Gehring and Krapohl 2007), implying that the Commission plays a modest role in the system. NAs are also responsible for following up Commission decisions nationally. Poor harmonization in this field has been a recurrent challenge, often explained by the mismatch between EU single market policy and member-state health policies (Permanand 2006; Permanand and Mossialos 2005; Greer 2013; Hauray 2013). Recent controversies have shown that the member-states and Community institutions have different approaches to pharmaceutical regulation, as with the cost-benefit analysis related to the authorization of pharmaceuticals (Vestlund 2015). In sum, the EMRN is dominated by mechanisms for member-state control, expected to lead to decentralized decision behaviour. The fact that organizational structure yet facilitates resource pooling under the co-ordination of an EU agency makes it reasonable to believe that similar, centralized behavioural patterns can be found also in other networks that have mechanisms for member-state control and are seen as intergovernmental arrangements.

In this article, intra-network decision behaviour and the importance of organizational structure are studied empirically by examining who (which actors and whose arguments), and what (which concerns, problems, and solutions) officials pay attention to (or do not) in performing tasks related to EU policy administration. The aim is to identify how resource pooling takes place, and the extent to which behavioural patterns reflect organization structure. The article builds on official documents and 32 interviews 
with officials from the Commission (DG SANCO) and EMA as well as the Norwegian Medicines Agency (NOMA) and the Slovak State Institute for Drug Control (SIDC), the Norwegian Ministry of Health and Care Services (NMH) and the Slovak Ministry of Health (SMH) (see Appendix). Interviewees were chosen based on their participation in and/or knowledge about inter-institutional relationships in the EMRN, to provide perspectives on intra-network decision behaviour at the EU and national level. Agency informants cover several hierarchical levels and all sections except for HR, IT and Finance. Commission, EMA and ministry informants include senior- and lower-level officials. Interviewees were asked to describe co-operation in the EMRN, who and what are important in the network, whom they interact with, the frequency of interaction, the 'content' of interaction (exchange of views, information, best practice, etc.), the type of task interaction (formulation, transposition and/or application of EU policy) and the importance attributed to network interaction (actors, agreements, arguments).

There are certain limitations to the data. First, only two NAs were included. However, the intention was not to draw on a 'representative' sample and generalize about the characteristics, beliefs, or actions of the full population of network participants, but to capture the in-depth perspectives and testimonies of individuals closely involved in the processes of interest (Tansey 2007: 769). Second, as both NAs are among the smaller agencies in the network, interviewees may over-emphasize the occurrence and importance of resource pooling. Interviews with Commission and EMA officials should help to balance the material; interview data were also supplemented with secondary literature and official documents, including EMA documents annual reports, minutes from EMA management board meetings, EMA rules of procedures and EMA's 
founding regulation. Using data from several sources contributes to triangulation and strengthens the robustness and credibility of the findings (Tansey 2007: 766).

\section{INTRA-NETWORK DECISION BEHAVIOUR: POOLING ADMINISTRATIVE}

\section{RESOURCES}

The interviews show that decision behaviour in the network is characterized by NAs pooling administrative resources under EMA co-ordination in two ways. First, network participants routinely interact and share valuable assets such as knowledge, information, practices and experiences. Second, there is a routinized division of labour, with participants mutually adapting and specializing in different types of tasks and different fields of expertise.

With regard to sharing of assets, officials from both NAs and EMA report that they are in ongoing contact with each other through regular meetings (committees, working groups, the EMA Management board and informal networks), procedures, e-mails, phone calls and teleconferences. Whenever SIDC and NOMA officials face new problems, topics, cases, or actors, they routinely consult the network on information, practices, experiences and solutions. NA officials also report that they are regularly consulted by officials in sister agencies. This occurs regardless of policy phase or whether it is a national or EU matter (a distinction not always easy to make), and pertains to general problem-solving as well as handling of individual cases (such as product evaluations and company complaints), court cases and advice to ministries (such as development of new legislation or transposition of specific rules to national legislation). Concerning the division of labour, interviewees describe how NAs increasingly adapt to and complement each other in the EMRN. There used to be 
considerable differences among network members in how they assessed drugs, but the differences are becoming less distinct. Especially after the new system came into place in 1995, countries have become more co-ordinated, and now specialize in different tasks and areas of expertise.

Committee participants have different areas of expertise. Some agencies are competent in certain areas, and we appreciate that the committee covers different disciplines and that members complement each other. We might be concerned that we have slightly different points of view, but we also proactively try to calibrate ourselves in relation to each other (NOMA)

There are more and more products coming, and member-states concentrate on various aspects in order to save resources [...]. Everybody cannot do everything in the network. Some member states are perfect experts within specific fields, and some are not. Therefore, some differentiation and focusing of work is necessary (SIDC)

This implies that SIDC and NOMA rely on tasks conducted by other network participants, such as evaluations of products and companies, development of standards and guides for best practices as well as advice to MA applicants and consumers. Further, with the division of labour, SIDC and NOMA do not need in-house expertise on all issues, but can adapt to existing expertise in the network and concentrate on specializing in fewer scientific areas. For NOMA, this has meant a downscaling of activities in relation to the $\mathrm{CP}$, with a focus on four particular scientific fields.

NOMA has, and so have most of the other countries, selected priority areas. [...] We seek to work only with these products when tasks come up; we submit applications and show that we have experience with the products or similar products (NOMA)

We cannot have equal expertise in everything, and this collaboration is very important to get access to the best professional assessments in all fields of expertise. EMA evaluations constitute the foundation of NOMA's authorization of medicines in Norway (NOMA)

The specific areas were chosen based on existing in-house expertise and aims of improving it. Earlier NOMA contributed to the network in several fields, but 'Now we never apply [for EMA assignments] outside those areas. So you become more 
competent, you do a good job, the quality is good, you submit in time and get good feedback from EMA’ (NOMA). Also with SIDC, mutual adaptation has made it possible to narrow the scientific focus. SIDC has until recently relied on external experts but is now in the process of building up in-house expertise. The aim is to specialize in a few specific scientific areas so they can contribute more to the EMRN and influence scientific decision-making. In this process SIDC is actively seeking advice and has been assisted by sister agencies on which areas to specialize and how.

We try to focus on specific processes. Our aim is not to be experts in every field, but we try to focus on specific aspects and we try to use the resources and expertise of other medicines agencies (SIDC)

\section{EMA: CO-ORDINATING RESOURCE POOLING}

EMA co-ordinates resource pooling and also contributes scientific and legal expertise as well as institutional memory and procedural knowledge. The EMA secretariat facilitates interaction among network participants and ensures the smooth functioning of the system. It organizes and hosts all committee meetings on their premises in London, including booking flights and hotel accommodation for participants (national officials). EMA serves as secretariat for all committees, receiving MA applications from pharmaceutical companies and finalizing and submitting scientific opinions to the Commission. The EMA secretariat constitutes an important intermediary between the NAs and Commission, which plays a modest role in the network. In addition, the EMA secretariat distributes network tasks among NAs (for instance, scientific assessments and inspections) and formulates guidelines, standards, templates and best practices.

At any time, we probably have about a hundred European experts from national regulatory agencies in house at various different meetings. They are an essential part of our day-to-day work (EMA) 
The secretariat's centrality is shown by how it distributes tasks among NAs. MA applications are submitted directly to EMA, which appoints a product team (PT) for each case. The PT is the applicant's contact point, co-ordinating the process with the two rapporteur agencies and ensuring that evaluations follow written procedures and timelines. The team leader also provides the assessment teams with relevant information EMA already holds on a product, which may date back several years (EMA 2014b). We have a product team internally working with the rapporteur and co-rapporteur. We have a leader who is usually responsible for safety and efficacy; we have somebody who contributes on the quality aspects, somebody on the inspections, on risk management, on regulatory affairs, and on medical information (EMA)

It is a scientific technical procedural support role to the assessment team at the national level. Usually it would be people with a pharmacy or a medical degree who are also very familiar with the regulatory framework and with the procedures, so that they can give all the operational support that is needed. At the same time they are very well aware of the therapeutic class that they are looking after, so they often help the rapporteur to ensure consistency across products, or consistency with guidelines. There is a lot of quality control, peer review and scientific support done by the agency to the assessors. At the end of the process, they also work very closely together to draft the final assessment report. Then the PT looks at all the assessment reports that come through the review procedure, and they summarize it with one overall final assessment report (EMA)

To become rapporteur, NAs must submit written applications to the EMA secretariat, which takes the decision in co-operation with Committee chairs. The decision is based on the NAs' ability to deliver scientific assessments on time and expertise on the subject-matter. Although NAs receive fees for rapporteurships, these are low, and some assignments are more popular than others. If no NAs volunteer, EMA personnel will approach NA representatives at committee meetings and ask them directly. Further, EMA ensures legal consistency between scientific decisions through advice and establishment of standards. Officials report that EMA legal support is invaluable when they take on assignments in the network. EMA increasingly also provides scientific 
support: for example, applications within the orphan and paediatric areas are

scientifically assessed by the EMA team before the evaluation process by NAs.

There is close co-operation with EMA. The EMA co-ordinator is part of the team and will always be central to discussions, dialogue and process: technically as contact persons, but they are also central in academic discussions. They are scientific co-ordinators, not merely administrative co-ordinators. [...] And useful in the regulatory area - many committee representatives don't have regulatory experience (NOMA)

They are definitely a special agency. EMA provides not only co-ordination of scientific expertise, but is also a driver for training, harmonizing procedures and setting standards. This has influence on the member states, I would say [...] I can provide you with one example - transparency is a topic in the EU at the moment. EMA is setting the rules for transparency and declaration of interests and the general strategy in that area (SIDC)

\section{THE RELEVANCE OF ORGANIZATIONAL STRUCTURE IN EXPLAINING}

\section{RESOURCE POOLING}

\section{The importance of horizontal specialization}

As the EMRN brings together officials from organizational units with compatible organizational structures and shared sector affiliation, horizontal specialization could be expected to encourage resource pooling by focusing network participants' attention on similar, sector-specific problems and solutions. The relevance of shared sector affiliation in explaining resource pooling is demonstrated by how network participants focus on the same tasks, concerns, issues and actors, and also face similar problems and challenges. In addition to serving parent ministries with technical-scientific support, SIDC and NOMA are to ensure pre- and post-market surveillance of the quality, efficacy and safety of medicinal products, ensure accessibility and provide information to the public. This involves dealing with a complex environment of producers, consumers, and policy-makers with differing demands and needs. Officials frequently face ambiguous regulatory issues in formulation and implementation of national as well 
as EU policies. This spurs network participants' requests for and routinized sharing of knowledge, information, practices and experiences. Continuous interaction provides ample opportunities for discussing issues and challenges with other officials or in plenary, in turn enabling officials to learn how other NAs or EMA solve problems. Officials report that they get new ideas and inspiration from being part of a larger professional environment. Some officials have their closest colleagues in other NAs, because few (if any) in their own agency work on similar topics. NA officials may not always follow the advice from other network actors, but they find it helpful to view a specific case from several angles.

It has clearly been important both for my personal and professional development. You travel quite a lot and get impulses from other countries, from scientists that have different views. This gives you a broader perspective than what you get from working isolated in Norway. You develop more nuanced views and experience professional corrections (NOMA)

\section{The importance of vertical specialization}

As national agencies participating in the EMRN are vertically separated at the national level, they were expected to operate relatively freely in the EMRN, and NA officials could be expected to focus on professional-technical rather than national, political concerns, issues and views. This, in turn, was expected to encourage resource pooling among network participants. The main function of NAs in the network is to provide scientific expertise, and NA officials consider such knowledge as the major currency in a network where the focus is of a scientific-technical nature. 'If you provide with qualified input, and have skilled professionals in the pharmaceutical area, what is said will be taken into account. [...] The key is to provide good input' (NOMA). Committee discussions focus on the scientific-technical aspects of pharmaceuticals, with little promotion of national or political views. 'It is more about discipline than nationality. [...] The collaboration follows scientific lines' (NOMA). 
Both NA and ministry informants from Slovakia and Norway confirm that NAs operate independently as regards EMRN activities. EMA informants also confirm that they have little contact with ministry officials. In national administrative systems, ministries are formally responsible for EU policy formulation and transposition, and agencies for policy application and activities related to the EMRN. In reality, SIDC and NOMA perform tasks related all policy phases. Agency officials report that they co-ordinate with parent ministries on the formulation of formal national positions and transposition of EU legislation, but rarely experience ministry involvement in scientific-technical decision-making, except when controversial issues arise. Ministry interference could potentially hamper resource pooling in a network where co-operation follows professional lines and scientific arguments carry most weight. Ministries generally focus more on the financial aspects of medicines and are kept informed through various reporting routines.

\section{The importance of NA organizational capacity}

Lack of organizational capacity in NAs was expected to encourage resource pooling among network participants, and NAs' lack of expertise, staff and/or experience is an important explanatory factor here. Authorization procedures are complex and timeconsuming, requiring high technical skills and expensive expertise. Especially the smaller NAs recognize the potential benefits of economies of scale, but also larger agencies can benefit from pooling. Resource pooling assists officials in their daily work, and helps to lessen work burden of the national agencies. Officials in both SIDC and NOMA stress how being able to lean on network resources is timesaving, improving 
efficiency and overall performance - for instance, enabling them to introduce more products faster into their national markets.

Through EMA we benefit from the resources of the competent authorities in all member states and receive a faster and more thorough evaluation of new drugs [...]. Without participating in the system we would have had to evaluate all medicines ourselves. It would be very resource intensive and we would have lost much information on adverse effects and product safety (NOMA)

In this co-operation we can share knowledge and share work, which makes it easier to deal with limited resources (SIDC)

There are differences in how NAs contribute and benefit from the resource pool. Especially the Dutch, Swedish, British and German agencies are mentioned as 'big sisters'. These agencies have larger staffs and can specialize in a broader range of fields of expertise than the smaller agencies. Consequently they can be more involved in network activities by taking on more assignments and by scrutinizing and commenting on the work done by other agencies. These contributions are important to the resource pool, and the 'big sisters' are probably less dependent on the resource pool than are the smaller agencies. SIDC and NOMA officials explain that they must focus on the tasks and activities where they have direct responsibility.

Of course there are still big differences between the large agencies, for example the British, Swedish, and Dutch agencies, and small agencies, such as ours. In our department there are only four people in pharmacovigilance. It is really impossible to do the same as the large agencies do and we participate much less than the other agencies. (SIDC)

However, large agencies may benefit from the expertise and experience of sister agencies and EMA (EMA 2014b). For instance, NOMA specializes in cancer medicine, developing advanced expertise not necessarily found in a larger agency. Moreover, also big agencies face resource challenges. A recurrent topic at EMA management board meetings is that the functioning of the EMRN is under pressure due to general lack of 
resources among NAs, and that fees for conducting tasks in the network should be increased - some tasks are not compensated at all (EMA 2014b).

Furthermore, resource pooling has an extra dimension to officials in SIDC, related to its lack of professional experience and newcomer status in the EU system (see Martens 2008a). Since acceding to the EMRN, Slovakia has built a new regulatory system for pharmaceuticals. Assistance from the Commission, EMA and sister agencies has been vital for developing administrative, legal and scientific expertise, training administrative and scientific staff, and transposing and applying EU legislation.

It is really important that we are part of the European network [...] It is important for transfer of knowledge and skills, because we have been member of the EU for only ten years. We took over all the legislation and regulations concerning medicines, so it is really nice that we have had the other agencies to learn from, their experiences and their skills. We also had some projects that helped us to start and implement this knowledge here (SIDC)

Without the network, without EMA's role, EMA training and EMA setting guidelines and rules, it would be impossible for us as a newcomer to the EU (SIDC)

\section{The importance of EMA organizational capacity}

EMA was expected to be an important hub in the network, enabled by its organizational capacity to influence intra-network behavioural patterns and facilitate resource pooling. EMA has a central role in co-ordinating resource pooling in the network, and also contributes to the resource pool. The organizational capacity - experience, expertise and manpower - that EMA has gradually built up constitutes an important foundation. The EMA secretariat has grown significantly since 1995 and now has 785 employees (EMA 2014a; Groenleer 2009). Its initial task was to 'provide technical, scientific and administrative support for the committees and ensure appropriate co-ordination between them' (Regulation [EC] No 726/2004: 22). Over the years, its tasks and experience have 
expanded considerably, and now also include scientific support. EMA has established a reputation for being a strong, quasi-regulatory EU agency that co-ordinates national expertise efficiently and ensures high-quality scientific decisions (Gehring and Krapohl 2007; Groenleer 2009; Hauray 2013; Krapohl 2008). SIDC and NOMA officials perceive the EMA secretariat as a hub and primus inter pares in the network. EMA owes this status to its key position in all network activities, processes and procedures, giving it unique experience, knowledge and overview, as well as an informational advantage vis-à-vis other network participants. According to EMA informants, its current position would be difficult to fill with fewer resources. Given EMA's advantage as regards information, overview, knowledge and experience, it is also unlikely that a national agency could fill its position (even one of the 'big sisters'). Previous studies have shown that the Commission may have a strong role vis-à-vis networks in policy fields where it has administrative capacity (Martens 2006; Martens 2008a; 2008b; LeviFaur 2011; Versluis 2012; Egeberg et al. 2012): EMA seems to fill this function in the EMRN. Although not directly involved in day-to-day work, the Commission follows network activities closely via supervision of the EMA secretariat (Vestlund 2015).

\section{CONCLUDING DISCUSSION}

Scholars disagree on the effects of establishing administrative networks for EU policy administration and EU executive power. Some argue that intra-network decision behaviour is conditioned by formal delegation and legal arrangements, leading to intergovernmental, decentralized decision behaviour (Eberlein and Grande 2005; Kassim and Menon 2010; Kelemen and Tarrant 2011; Bickerton et al. 2014). However, a growing number of studies indicate that intergovernmental behavioural patterns are supplemented or replaced by behavioural patterns that cross national borders and levels 
of governments. Seeing decision behaviour as shaped by organizational structure, scholars argue that more centralized behavioural patterns occur due to the way networks are organized. This article has investigated how resource pooling takes place in EU administrative networks and the relevance of organizational structure in explaining its occurrence. The article adds to the literature through a study of intra-network decision behaviour in the EMRN, a least-likely case for organizational structure promoting centralized behavioural patterns. However, the findings show that, under the coordination of the European Medicines Agency (EMA), network participants pool resources in two ways: they routinely interact and share information, practices and experiences, and there is a routinized division of labour, with participants mutually adapting and specializing in different tasks and fields of expertise. Although resource pooling implies improved performance of individual participants (especially NAs that are small and/or new to the network), it also means that NAs (and to some extent their parent ministries) increasingly depend on the network to fulfil their functions in national administrative systems. Division of labour implies administrative integration that might reduce NA ability to support ministries in developing national policy positions, especially given that NAs continue to specialize in different scientific fields, becoming ‘centres of excellence' (see Groenleer 2009).

The study supports the claim that organizational structure contributes to centralize intranetwork decision behaviour. The findings indicate administrative integration and mutual influence across levels of government and national borders within the pharmaceutical sector. Given that EU agencies perceived as integral parts of the Commission's administration (Egeberg et al. 2015), resource pooling can be understood as a centralization of executive power at the EU level. This can be seen an indication of an 
emerging multilevel union administration (Egeberg 2006; Trondal 2010). The article thus contributes to the debate on the effects of establishing EU administrative networks by showing that networks may facilitate centralized decision behaviour patterns despite strong mechanisms for member-state representation and control as part of its governance structure.

The fact that resource pooling takes place in the EMRN despite the strong mechanisms for member-state control indicates that the concept of resource pooling may have relevance for a broader universe of cases. This study has focused on one network in one particular sector, so resource pooling as a more general phenomenon needs further investigation. However, the analysis has identified certain structural conditions that may be relevant in facilitating resource pooling also in other networks normally understood as intergovernmental: resource pooling is more likely when there is shared sector affiliation among network participants, NAs operating independently from parent ministries, NAs lacking certain organizational capacities, and given the presence of an EU agency with the capacity to administer pooling. The concept of resource pooling may hence have particular relevance in networks that involve EU executive bodies and NAs with similar roles (although different levels of government and member-states). Such dynamics may be found also where tasks are less political but require high technical-scientific expertise (as with the food and chemicals sectors); and where procedures are complex, time-consuming, NAs can benefit from economies of scale. Also, resource pooling seems more likely in networks where coordination requires skills, expertise and overview that only an EU-level executive body can acquire. While not suggesting that resource pooling is conditioned solely by organizational structure, this article shows that applying an organizational perspective to the study of EU 
administrative networks contributes to a better understanding of the effects of such administrative arrangements for intra-network decision behaviour than achieved by focusing solely on the effects of formal delegation and legal arrangements. 


\section{ACKNOWLEDGEMENTS}

XXX

\section{REFERENCES}

Bach, T. and Ruffing, E. (2013) 'Networking for autonomy?', Public Administration 91(3): $712-26$.

Bach, T., Ruffing, E. and Yesilkagit, K. (2015) 'The differential empowering effects of europeanization on the autonomy of national agencies', Governance 28(3): 285-304.

Bickerton, C.J., Hodson, D. and Puetter, U. (2014) 'The new intergovernmentalism', Journal of Common Market Studies 53(4): 703-22.

Busuioc, M., Groenleer, M. and Trondal, J. (eds) (2012) The Agency Phenomenon in the European Union, Manchester: Manchester University Press.

Curtin, D. and Egeberg, M. (2008) ‘Tradition and innovation: Europe’s accumulated executive order', West European Politics 31(4): 639-61.

Danielsen, O.A. and Yesilkagit, K. (2013) 'The effects of European regulatory networks on the bureaucratic autonomy of national regulatory authorities', Public Organization Review 14(3): 353-71.

Dyrdal, M. (2004) 'Legemiddeltilsyn og europeisering', Notat 10, Stein Rokkan Senter for flerfaglige samfunnsstudier, Bergen: Universitetsforskning Bergen.

Eberlein, B. and Grande, E. (2005) 'Beyond delegation', Journal of European Public Policy 12(1): 89-112.

Egeberg, M. (2006) Multilevel Union Administration, Basingstoke: Palgrave Macmillan.

Egeberg, M. (2012) 'How bureaucratic structure matters: an organizational perspective', in B.G. Peters and J. Pierre (eds), Handbook of Public Administration, London: Sage, pp. $157-68$. 
Egeberg, M. and Trondal, J. (2009) 'Political leadership and bureaucratic autonomy', Governance 22(4): 673-88.

Egeberg, M., Trondal, J. and Martens, M. (2012) 'Building executive power at the European level', in M. Busuioc, M. Groenleer and J. Trondal (eds), The Agency Phenomenon in the European Union, Manchester: Manchester University Press, pp. 19-41.

Egeberg, M., Trondal, J. and Vestlund, N.M. (2015) 'The quest for order', Journal of European Public Policy 22(5): 609-29.

EMA (2014a) 'Annual Report 2013', available at http://www.ema.europa.eu/ema/index.jsp?curl=pages/about us/document listing/docu ment_listing_000208.jsp\&mid=WC0b01ac058002933a.

EMA (2014b) Minutes of the $83^{\text {rd }}$ meeting of the Management Board, available at: http://www.ema.europa.eu/ema/index.jsp?curl=pages/about_us/general/general_content 000104.jsp\&mid=WC0b01ac0580028c31.

Gerring, J. (2007) Case Study Research, New York: Cambridge University Press.

Gehring, T. and Krapohl, S. (2007) 'Supranational regulatory agencies between independence and control', Journal of European Public Policy 14(2): 208-26.

Genschel, P. and Jachtenfuchs, M. (2013) 'Introduction: beyond market regulation', in P. Genschel and M. Jachtenfuchs (eds), Beyond the Regulatory Polity? The European Integration of Core State Powers, Oxford: Oxford University Press.

Gornitzka, Å. (2009) 'Networking administration in areas of national sensitivity', in A. Amaral, G. Neave, C. Musselin and P. Maassen (eds), European Integration and the Governance of Higher Education and Research, Dordrecht: Springer.

Greer, S. (2013) 'Introduction: what is European Union public health policy?', in S. Greer and P. Kurzer (eds) European Union Health Policy, London: Routledge. 
Groenleer, M. (2009) The Autonomy of the European Agencies, Delft: Eburon.

Gulbrandsen, C. (2011) 'The EU and the implementation of international law', Journal of European Public Policy 18(7): 1034-51.

Hauray, B. (2013) ‘The European regulation of medicines', in S. Greer and P. Kurzer (eds), European Union Health Policy, London: Routledge.

Hauray, B. and Urfalino, P. (2009) 'Mutual transformation and the development of European policy spaces', Journal of European Public Policy 16(3): 431-49.

Hofmann, H.C.H., and Türk, A. (2007) 'The development of integrated administration in the EU and its consequences', European Law Journal 13: 253-71.

Kassim, H. and Menon, A. (2010) 'Bringing the Member States back in', Member State Resurgence, and the Decline of the European Commission since the 1990s', ECPR fifth Pan-European Conference, Porto, 23-26 June.

Kassim, H., Peterson, J., Bauer, M., Connolly, S., Dehousse, R., Hooghe, L. and Thompson, A. (2013) The European Commission of the Twenty-First Century, Oxford: Oxford University Press.

Kelemen, D. (2002) 'The politics of “eurocratic" structure and the new European agencies', West European Politics 25(4): 93-118.

Kelemen, D., and Tarrant, A.D. (2011) 'The political foundations of the eurocracy', West European Politics 34(5): 922-47.

Krapohl, S. (2008) Risk Regulation in the Single Market, Basingstoke: Macmillan.

Levi-Faur, D. (2011) 'Regulatory networks and regulatory agencification', Journal of European Public Policy 18(6): 810-29.

Maggetti, M. (2014) 'The rewards of cooperation', European Journal of Political Research 53(3): 480-99.

Maggetti, M. and Gilardi, F. (2011) 'The policy-making structure of European regulatory 
networks and the domestic adoption of standards', Journal of European Public Policy 21(9): 1293-1310.

Martens, M. (2006) 'National regulators between union and governments', in M. Egeberg (ed.), Multilevel Union Administration, Basingstoke: Palgrave Macmillan.

Martens, M. (2008a) 'Administrative integration through the back door?', Journal of European Integration 30(5): 635-51.

Martens, M. (2008b) 'Runaway bureaucracy?', Scandinavian Political Studies 31(1): 27-43.

Newman, A. L. (2008) ‘Building transnational civil liberties’, International Organization 62(1): 103-30.

Ossege, C. (2015) European Regulatory Agencies in EU Decision-Making: Between Expertise and Influence, Basingstoke: Palgrave Macmillan.

Permanand, G. (2006) EU Pharmaceutical Regulation, Manchester: Manchester University Press.

Permanand, G. and Mossialos, E. (2005) 'Constitutional asymmetry and pharmaceutical policy-making in the European Union', Journal of European Public Policy, 12 (4): $687-709$.

Regulation (EC) No 726/2004 of the European Parliament and of the Council of 31 March 2004 laying down Community procedures for the authorisation and supervision of medicinal products for human and veterinary use and establishing a European Medicines Agency, OJ L136/1, pp. 1-33.

Tansey, O. (2007) 'Process tracing and elite interviewing: a case for non-probability sampling', Political Science \& Politics 40(4): 765-72.

Trondal, J. (2010) An Emergent European Executive Order, Oxford: Oxford University Press. Trondal, J. (2014) ‘Agencification', Public Administration Review 74(4): 545-49. 
Trondal, J. and Peters, B.G. (2013) 'The rise of European administrative space', Journal of European Public Policy 20(2): 296-307.

Versluis, E. (2012) 'Catalysts of compliance?', in M. Busuioc, M. Groenleer and J. Trondal (eds), The Agency Phenomenon in the European Union, Manchester: Manchester University Press.

Vestlund, N. M. (2015) ‘Exploring EU Commission agency relationship’, in M. Bauer and J. Trondal (eds), The Palgrave Handbook of the European Administrative System, Basingstoke: Palgrave Macmillan.

WHO (2002) Drug Information, 16(4), available at http://apps.who.int/medicinedocs/pdf/s4952e/s4952e.pdf.

Yesilkagit, K. (2011) 'Institutional compliance, European networks of regulation and the bureaucratic autonomy of national regulatory authorities', Journal of European Public Policy 18(7): 962-79.

\section{APPENDIX}

The interview data was gathered in several rounds since 2008 and consists of interviews with 14 NOMA officials (12 in November-December 2008, two in April-May 2013); two NMH officials (November 2008, November 2011); three EMA officials (April-May 2013); three Commission (DG SANCO) officials (two in December 2011, one in May 2013); and eight SIDC officials and two SMH officials (April 2014). Informants from Norway were chosen due to access. NOMA has 250 employees and is organized under the NMH. Norway is not a member of the EU but is a full member of EMRN through the Agreement on the European Economic Arena (EEA) (except for voting rights in decision-making). Through the EEA agreement Norway has access to the single market and has committed itself to implement EU legislation. NOMA had observer status in 
committees and working groups under the Commission and EMA from 1998, and full access to the EMRN from 2000 (Dyrdal 2004: 15).

SIDC was included in order to increase the number of observations and richness of the data material. SIDC has 170 employees and is organized under the SMH. SIDC obtained observer status in the Pharmaceutical Committee (under the Commission) and an EMA working group in 1997, and started preparations for adopting EU regulations and standards (WHO 2002). SIDC obtained full access to the EMRN when Slovakia became an EU member in 2004. Hence, both Norway and Slovakia have participated in the EMRN for a long time, and their officials should be well qualified to provide information about the network. 